\title{
Effects of Billboards on Buying Behavior of Customer in Context of Textile Products
}

\author{
Dr Saima Akhtar \\ Assistant Professor, Department of Public Administration, University of Karachi
}

\begin{abstract}
The purpose of this study is to determine the effects of Billboard and related media on consumer behavior using lawn products with the focus on three perceptual processes, selective attention, selective distortion and selective retention. Data for the study was collected using questionnaire consisting of 15 questions. Survey was conducted on 150 people including students of University of Karachi and the General public at different malls. Simple frequency tables, $T$ test and SPSS were used to analyze and report the findings of the study. Findings of the research revealed that people find billboards of various products attractive and they do pay attention to the Billboards of lawn products; they distort the information and retain it which later aids them in recalling the brand. So it is suggested that marketers of lawn product continue using the Billboards as it is a good source of informing the customers about their brands. However, they need to work on making the customer believe that they will get whatever they see.
\end{abstract}

Keywords: Billboards, Consumer Buying Behavior, selective attention, selective distortion, selective retention, Textile products

DOI: $10.7176 / \mathrm{JESD} / 10-10-06$

Publication date:May $31^{\text {st }} 2019$

\section{Introduction}

Perception is to organize, identify and interpret sensory information in order to understand the environment. In other words, perception is interpreting the world around you and making sense out of it in your brain. This is done via stimuli that affect your different senses — sight, hearing, touch, smell, and taste. How you combine these senses also makes a difference. Since every person is different they come up with different combinations.

Consumers have perceptions about different businesses and their products which definitely have a great impact on their buying behavior. That is the reason why organizations spend billions of rupees in marketing themselves and influencing the perception of the target consumers favorably. With proper planning and execution organizations can influence the perceptions which will result in profitable consumer behavior.

Selective perception is filtering the original message and retaining only that part of information which attracts and is acceptable to us. It also means selecting only that information that supports our beliefs and opinions and ignoring the ones which are against our beliefs. As a result of filters and other avoidance techniques many marketers are experiencing lower response rates to their campaigns. (Wells, Moriarty \& Burnett, 2016)

According to the selective perception theory we filter stimuli both consciously and unconsciously as we perceive the stimuli. We can consciously focus our attention on specific stimuli and disregard unimportant, distracting, contradicting information. In other words we actively choose what information we digest and what we discard. Selective perception can also happen unconsciously as well without any purposeful effort on our part.

Selective perception is a form of bias that causes people to perceive messages and actions according to their frame of reference. Using selective perception, people tend to overlook or forget information that contradicts their beliefs or expectations.

Consumer behavior is influenced by many things, including environmental and marketing factors, the situation, personal and psychological factors, family, and culture. Businesses try to figure out trends so they can reach the people most likely to buy their products in the most cost-effective way possible. Businesses often try to influence a consumer's behavior with things they can control such as the layout of a store, music, grouping and availability of products, pricing, and advertising. While some influences may be temporary and others are long lasting, different factors can affect how buyers behave-whether they influence you to make a purchase, buy additional products, or buy nothing at all.

Another key factor in influencing consumer perception is exposure. The more information consumers have about a product, the more comfortable they are buying it. As a result, businesses do all they can to publicize their offerings. However, this causes a problem: When every business bombards consumers with marketing messages, consumers tend to tune out. To influence consumer perception, a business not only must expose its product to consumers, it also must make its product stand out from the crowd so that it can get the attention of the consumer

Consumers are bombarded with messages on television, radio, magazines, the Internet, and even bathroom walls. The average consumer is exposed to about three thousand advertisements per day. Kalle Lasn, Culture Jam: The Uncooling of America (New York: William Morrow \& Company, 1999). Consumers are surfing the Internet, watching television, and checking their cell phones for text messages simultaneously. However only a part of that 
information could make it to our brains and even a part of it is retained.

Most of the times we are perceptive to advertisements of the products we need and we pay attention to only those. And when we do so we are indulging in selective attention. Selective attention is the process of filtering out information based on how relevant it is to you and paying attention to only selected things. It's been described as a "suit of armor" that helps you filter out information you don't need. At other times, people forget information, even if it's quite relevant to them, which is called selective retention. Often the information contradicts the person's belief. For example a chain smoker would not pay any attention to the anti-smoking messages in the commercial. To be sure their advertising messages get through to you and you remember them, companies use repetition. Do you remember how many times the same commercial is repeated during a television program? That is one way of making sure the customer retain the advertisements. Another potential problem experienced is selective distortion or misinterpretation of the intended message. Promotions for weight loss products or fairness product show models that look slim and trim after using their products, but consumers may not believe them and distort the information according to their beliefs. The same thing can happen with many types of messages.

Hence, our focus here in this paper is on these three perceptual processes that is selective attention, selective distortion and selective retention. We have different perceptions of the same object because of these three perceptual processes that is, selective attention, selective distortion and selective retention. As mentioned earlier selective attention is paying attention to selective things screening out the rest, selective distortion is the tendency to interpret information in a way that fit our preconceptions and selective retention is to retain only the part of what we have selectively perceived. This particular study is conducted to find out if people pay attention to the billboards of lawn among the cluster of hundreds of innovative Billboards of other products, it also aims to find out if they accept the messages as it is or distorts them according to their beliefs and if they retain the billboard advertisement of different brand which will later aid them in recalling the brand and motivate them to buy it.

Billboard is the only medium which cannot be ignored or avoided by the consumer like any other medium. As streets are normally crowded and people are moving slowly, they will notice the billboard whether they like it or not, plus people normally travel the same route repeatedly, means that probability of seeing the billboard regularly and retaining it for a longer time increase. Billboards also have advantage of reaching people who do not use other mediums. TV channels can be switched easily; Print ads can be avoided by simply turning the pages while billboard on the other hand cannot be avoided as everyone is out on the road for one reason or the other. The importance of billboard as an advertising medium has increased as people are spending less time in front of TV or at home and more time in transit. There are 4481 different kinds of out of home media used in Karachi alone and its increasing with each passing day. Hence the marketers of Lawn not only have to compete with other producers of lawn but with the advertisers of other hundreds of other products. If people notice this billboard and get attracted half the battle is won plus it is a good medium to attract the impulse buyer. If advertisers do an excellent job of creating a simple and bold advertisement, there is no way customer can ignore them and get attracted by them. For this purpose advertisers are paying attention to the size of the billboards, their location, colors, images, models used.

\section{Literature Review}

In marketing, perceptions are more important than the reality, as it is perceptions that will affect consumer's actual behavior. Different people perceive the same thing at the same time in different ways. Similarly the same individual may perceive the same thing in a number of ways. (William Pride) Perception is defined as the reception of stimuli through the senses and the attachment of meaning to various stimuli received. Perception is very selective (Olujimi Kayode) People can emerge with different perceptions of the same object because of three perceptual processes, selective attention, selective distortion and selective retention (Philip Kotler). These processes result in information alteration or distortion of what we do not like. The individual may remember only that part of information that supports his attitude and beliefs.

In today's economy, advertising and promotions play a significant role in marketing campaigns. Traditionally, one of the ways to deliver promotional messages has been via use of billboards and posters located in public places. Creating Effective billboards require good coordination among graphic designers, printing houses, advertising agencies and billboard owners

Billboards are normally designed and located in areas where the audience size may be classified as large, enabling a mass marketing approach. Hence it allows us to reach large number of target customer at a very low price.

Marketing strategies for billboards would be quite different like the messages must be very concise and focused; otherwise the vehicle occupant is gone before there is opportunity to grasp the purpose of the ad Graphic content of the billboard must be very large to be visible, and configured to attract attention in the blink of an eye. Accordingly, both the logistics and content of billboard advertising require a different mentality in design, construction and use, as compared to other marketing techniques. Many businesses, however, rely on billboard advertising to access consumers as part of their marketing program. It is also recognized that such advertising 
stimulates sales, leading to increased profits.

Customers are bombarded with hundreds of messages competing for their attention, but each person comprehends, accept and retain only a few. As Kotler $(1995,2000)$ states perception is the process used by people to select and to organize external stimuli giving them sense. However, everyone receives, organizes and translates these stimuli in a personal way; this occurs in relation with 3 perceptive processes: selective attention, selective distortion, and selective retention. We are exposed to hundreds of ads everyday but we pay attention to only a few. (Etzel, Walker, Stanton). That is of all the billboards of various product you are exposed to while driving you pay attention to selective ones. Then you compare the information with your existing store of knowledge and you retain only part of what was selectively perceived.

Billboard advertising is one where marketers and advertisers target customers such as passengers, drivers and people who are walking (Shirky 2010). According to Woodside (1990) primary advantage of Billboard over other media is its high frequency of exposure. It is unavoidable by people as everyone is out on the road for one reason or the other. Woodside also concluded that outdoor advertising is likely to be effective in increasing sales. The Importance of Billboard can be gauged by the fact that about seventy one percent of travelers look at the billboard messages and about one third look at the billboard ad each or most of the time they pass one (Williams, 2009). Billboard advertising is the only mass medium which reaches consumers as they go about their lives every day (Iverson 2011). It is likely for consumers to see the same billboard more than once a day in various locations (Adsource Outdoor). Marketers are adding so much creativity in designing the Billboard it is impossible to ignore them. Billboards stretch the boundaries of creativity to increase ad awareness and grab customer's attention (Outdoor Advertising Association of America). A study of billboard users found that compared with other media, billboards were rated higher in terms of ability to communicate information affordably, attract new customers, and increase sales (Taylor and Franke, 2003). Another component of effective advertisement that creates emotional response is the consumer ability to recall the brand ad (Goldsmith and Lofferty, 2002). Thus, the relative importance of brand recall will depend on the extent to which consumer makes product related decisions, which leads to the brand awareness (Keller, 2006).This brand awareness help in ensuring the recall ad, which has the competitive advantage over those brands that are not recalled easily. Thus positive attitude towards ads have more ability to recall the ads then those having negative attitude (Goldsmith and Lofferty, 2002).Through advertisement brand knowledge helps in influencing brand salience in such a way, that the quantity and freshness of the memories about the brand thought to be in buying situation that creates emotional response towards ads (Holden and Lutz, 1992). Brand promoted through Billboards are more remembered than any other media (Azhari and Kamen). The media selected to communicate to consumers goes a long way in making the positive impact of the organizations and its products.(Warshaw and Kinnear, 1983). Media planners must carefully select the mix of media that maximizes the chance of exposing the target segment to company's advertisement to have maximum exposure and have beneficial impact on the consumer (Olujimi Kayode).

\section{Method of Data Collection}

The study was conducted to find out if people pay attention to Billboards of lawn product and if they believe in the information provided through Billboard and if it helps the customer in retaining the information and aids them in their buying decisions. For this purpose primary data was collected using structured questionnaire consisting 15 questions.

Convenient sampling method was used and the size of the sample taken in this study was 150 . Students of Karachi University and general people from different malls were used as the sample. Likert scale with five points was used to find out how much the participants agree or disagree with the statement. It helped in capturing the intensity of their feeling for a given item. To evaluate the hypothesis simple $\mathrm{T}$ test and frequency tables have been deployed.

\section{Research Hypothesis}

$\mathbf{H}_{1}$ : Billboard advertising of lawn products get the attention of customers (people pay attention to selective things)

H2: Repetitively watching the Billboards will affect customer decision (motivate them to buy the brand)

$\mathbf{H}_{3}$ : The message on Billboard is believed by the customer (people distort information) 
Data Analysis and Presentation

Frequencies

Statistics

\begin{tabular}{|ll|l|l|l|}
\hline & Selective Attention & Selective Distortion & Selective Retention \\
\hline \multirow{2}{*}{$\mathrm{N}$} & Valid & 150 & 150 & 150 \\
& Missing & 0 & 0 & 0 \\
\hline
\end{tabular}

\section{Selective Attention}

\begin{tabular}{|ll|l|l|l|l|}
\hline & Frequency & Percent & Valid Percent & Cumulative Percent \\
\hline \multirow{6}{*}{ Valid } & Strongly Disagree & 4 & 2.7 & 2.7 & 2.7 \\
& Disagree & 35 & 23.3 & 23.3 & 26.0 \\
& Not Sure & 32 & 21.3 & 21.3 & 47.3 \\
& Agree & 49 & 32.7 & 32.7 & 80.0 \\
& Strongly Agree & 30 & 20.0 & 20.0 & 100.0 \\
& Total & 150 & 100.0 & 100.0 & \\
\hline
\end{tabular}

\section{Selective Distortion}

\begin{tabular}{|ll|l|l|l|l|}
\hline & Frequency & Percent & Valid Percent & Cumulative Percent \\
\hline \multirow{6}{*}{ Valid } & Strongly Disagree & 23 & 15.3 & 15.3 & 15.3 \\
& Disagree & 42 & 28.0 & 28.0 & 43.3 \\
& Not Sure & 42 & 28.0 & 28.0 & 71.3 \\
& Agree & 39 & 26.0 & 26.0 & 97.3 \\
& Strongly Agree & 4 & 2.7 & 2.7 & 100.0 \\
& Total & 150 & 100.0 & 100.0 & \\
\hline
\end{tabular}

\section{Selective Retention}

\begin{tabular}{|ll|l|l|l|l|}
\hline & Frequency & Percent & $\begin{array}{l}\text { Valid } \\
\text { Percent }\end{array}$ & Cumulative Percent \\
\hline \multirow{6}{*}{ Valid } & Strongly Disagree & 6 & 4.0 & 4.0 & 4.0 \\
& Disagree & 18 & 12.0 & 12.0 & 16.0 \\
& Not Sure & 15 & 10.0 & 10.0 & 26.0 \\
& Agree & 103 & 68.7 & 68.7 & 94.7 \\
& Strongly Agree & 8 & 5.3 & 5.3 & 100.0 \\
Total & 150 & 100.0 & 100.0 & \\
\hline
\end{tabular}

\section{T-Test}

One-Sample Statistics

\begin{tabular}{|l|l|l|l|l|}
\hline & $\mathrm{N}$ & Mean & Std. Deviation & Std. Error Mean \\
\hline Selective Attention & 150 & 3.4400 & 1.13208 & .09243 \\
Selective Distortion & 150 & 2.7267 & 1.09236 & .08919 \\
Selective Retention & 150 & 3.5933 & .91297 & .07454 \\
\hline
\end{tabular}

\section{One-Sample Test}

\begin{tabular}{|c|c|c|c|c|c|c|}
\hline & \multicolumn{6}{|c|}{ Test Value $=4$} \\
\hline & \multirow[t]{2}{*}{$\mathrm{t}$} & \multirow[t]{2}{*}{$\mathrm{df}$} & \multirow[t]{2}{*}{$\begin{array}{l}\text { Significance } \\
\text { (2-tailed) }\end{array}$} & \multirow[t]{2}{*}{$\begin{array}{l}\text { Mean } \\
\text { Difference }\end{array}$} & \multicolumn{2}{|c|}{$\begin{array}{l}\text { 95\% Confidence Interval of the } \\
\text { Difference }\end{array}$} \\
\hline & & & & & Lower & Upper \\
\hline Selective Attention & -6.058 & 149 & .000 & -.56000 & -.7427 & -.3773 \\
\hline Selective & -14.277 & 149 & .000 & -1.27333 & -1.4496 & -1.0971 \\
\hline Selective Retention & -5.455 & 149 & .000 & -.40667 & -.5540 & -.2594 \\
\hline
\end{tabular}

All 150 questionnaires were valid and none of them were missing. From the data present in the above tables 
we can infer that among hundreds of eye catching Billboards of various products, customers are exposed to everyday, they do pay attention to the Billboards of lawn products. More than $50 \%$ of the respondents agree that out of all the appealing and attention getting billboards of various products they also watch the billboards of lawn products and find them very pleasing. In fact with the kind of sizes of billboards, design, images and models used by the advertisers it is impossible for anyone on the road to miss the Billboards. They are no doubt playing a big role in creating the impact and it is impossible for anyone to ignore them. It also aids them in recalling the brand as the consumer uses the same route and watching the same brands every day later aids them in making their purchases. More than $70 \%$ of the respondents believe that it does a good job of reinforcing. However they distort the information given there. More than $70 \%$ either disagrees or not sure about what is shown and the message given on the billboards. People do get attracted by the prints and design but they are not sure about the quality that is they see the difference in the quality shown on billboards and the one they get in the shop.

\section{Conclusion}

Billboard advertising is becoming somewhat mandatory for the marketers of lawn products as people are getting tuned to watch the billboards for the upcoming launch of the product. Despite the rise of radio, television and internet advertising, the Billboard advertising has managed to make a place for itself. The three perceptual processes selective attention, selective distortion and selective retention play a very important role in consumer decision making. People cannot pay attention to all the billboards they are exposed to in limited time they have while passing on the road. Advertisers are continuously coming up with new and innovative ways to grab the attention of customers and they are successful in it to a great extent. Hence Marketers have to be innovative in designing their billboards as they as competing with not only the marketers of the same product but with hundreds of other products. They can do so by focusing on the size, color, images, location and the models used. They also have to make efforts in building the image and making the customers believe in their products/brands and accept the information given to them without distorting it. And as the customer takes the same route everyday going to work and coming back from work plus billboards are placed at different major intersections it helps them in retaining the information for a long time.

\section{References}

1. Armstrong, Gary and Kotler, Philip (2000) “Marketing: An Introduction”, Prentice- Hall, Upper Saddle River, New Jersey

2. Bhargava, M. and N. Donthu, and Rosanne Caron (1994), "Improving the effectiveness of outdoor advertising", Journal of Advertising Research, Mar/Apr 1994, pgs 46-55

3. Etzel, Walker, Stanton, "Marketing”, 13 Edition

4. Kotler, P. (1999), "Marketing Management", 10th edition, Prentice Hall Kotler, Keller

5. Koshy, Jha (2010), "Marketing Management-A South Asian Perspective”, 13th Edition PEARSON, and Prentice Hall

6. Mustafa, G., Sukran, K., \& Olgun, K. (2007). "The effects of outdoor advertisements on consumers: A case study". Studies in business and economics, 5(2), 70-88

7. Taylor, C. and G. Franke, 2003. "Business perceptions of the role of billboards in the U.S. economy". Journal of Advertising Research, June, 43(2): 150-161

8. Wells, Burnett, Moriarty, “Advertising Principles and Practices”, Fourth Edition, Prentice Hall

9. Stephen Hill \& Bevis Fenner, (2010) "Media and Cultural Theory”. Stephen Hill, Bevis Fenner \& Ventus Publishing

10. Rick T. Wilson, Brian D. Till, “Effects of outdoor advertising: Does location matter?”, Journal of Psychology \& Marketing, 3 August 2011

11. Anne C. Osborne \& Renita Coleman, "Outdoor Advertising Recall: A Comparison of Newer Technology and Traditional Billboards”. Journal of Current Issues and Research in Advertising, 30(1) March 2008, Pages 1330

12. William Pride \& O.C.Ferrell, (2010) "Marketing”, 2010 Ed., Mason, Ohio ; Australia : South Western Cengage Learning

13. Dr Brenda Mcarthy, (2016) "Consumer Behavior and PR", $1^{\text {st }}$ Edition

14. Katherine N Lemon and Peter C Verhoef, (2016) "Understanding Customer experience throughout the customer journey," Journal of Marketing, Volume: 80 issue: 6, page(s): 69-96

15. Olujimi Kayode, (2014) "Marketing Communications", 1st Edition, Bookboon. 